

\section{Methods to locate derelict fishing gear in marine waters}

This document was created for the Catalyze and Replicate Solutions Working Group of the Global Ghost Gear Initiative (GGGI). The purpose of the document is to assist prospective solutions project managers by providing a general overview of methods and techniques used globally to locate abandoned, lost, or otherwise discarded fishing gear (ALDFG) in marine habitats. The document describes a number of methods used; provides general techniques, benefits and limitations of the methods; and provides contact information of individuals and entities experienced in the methods.

Locating ALDFG is undertaken for two main reasons: to answer research questions related to the fate and transport of lost fishing gear and to remove lost fishing gear from marine waters, thus eliminating its harmful impacts to species and habitats. This document focuses on location methods best used if eventual removal of ALDFG is desired. Methods used to model ALDFG fate and transport at large geographic scales or to infer the locations of ALDFG based on ocean circulation, etc. are not explained here. To begin exploring these methods, we recommend accessing the 2012 special issue of the Marine Pollution Bulletin Volume 65, which focuses on at-sea detection of the ALDFG in the North Pacific Ocean.

If location of gear is undertaken to remove gear, project managers must determine whether location of lost gear will be conducted prior to launching gear removal operations or whether gear location and removal work will be conducted together. Simultaneous location and removal operations can be successful if managers have a good general knowledge of where the gear is located or confidence that concentrations of lost gear occur in a general area. In many fisheries throughout the world, the extent and location of lost fishing gear is unknown. The following methods can assist in initial assessments of locations and concentrations of lost gear to inform and guide subsequent removal operations.

Selected case studies highlighting the methods described are included, and contact information is given for individuals experienced using the various methods explained herein. If attempts to contact these individuals for further information indicate that their contact information is out of date, or they are not responding, please contact gggi@worldanimalprotection.org for assistance. 
Methods

The lost fishing gear location methods discussed in this document include:

- Sonar surveys

- Surface visual surveys

- Underwater visual surveys

- Dragging or grappling surveys

- Fisheries data and local knowledge

\section{Acoustic sonar surveys}

Underwater acoustic sonar surveyors can image predetermined areas of the seafloor. Scanning sonar equipment is deployed at a resolution adequate to depict objects that are less than $1 \mathrm{~m}$ in diameter. Sonar scanning can be deployed at a variety of depths and has been used to locate ALDFG in waters to $100 \mathrm{~m}$. It has been used to detect lost nets in the Adriatic Sea and in Brazil. Sidescan sonar scanning can cover large areas and can be deployed off of a moving vessel at low speeds. Sector scanning is appropriate for smaller areas of interest (like a harbor or rocky outcrop) and can be deployed from stationary tripods or poles placed on the seafloor. Sidescan sonar has been used effectively to locate ALDFG in a variety of locations worldwide. In the United States, sidescan sonar surveys are used to detect lost shellfish pots in Chesapeake Bay and in Puget Sound and the method has been used to locate lost nets as well. Sidescan sonar surveys have also been used in Brazil and in the Gulf of California to augment boat-based surveys. Sector scanning has been used effectively to locate ALDFG in the Adriatic Sea.
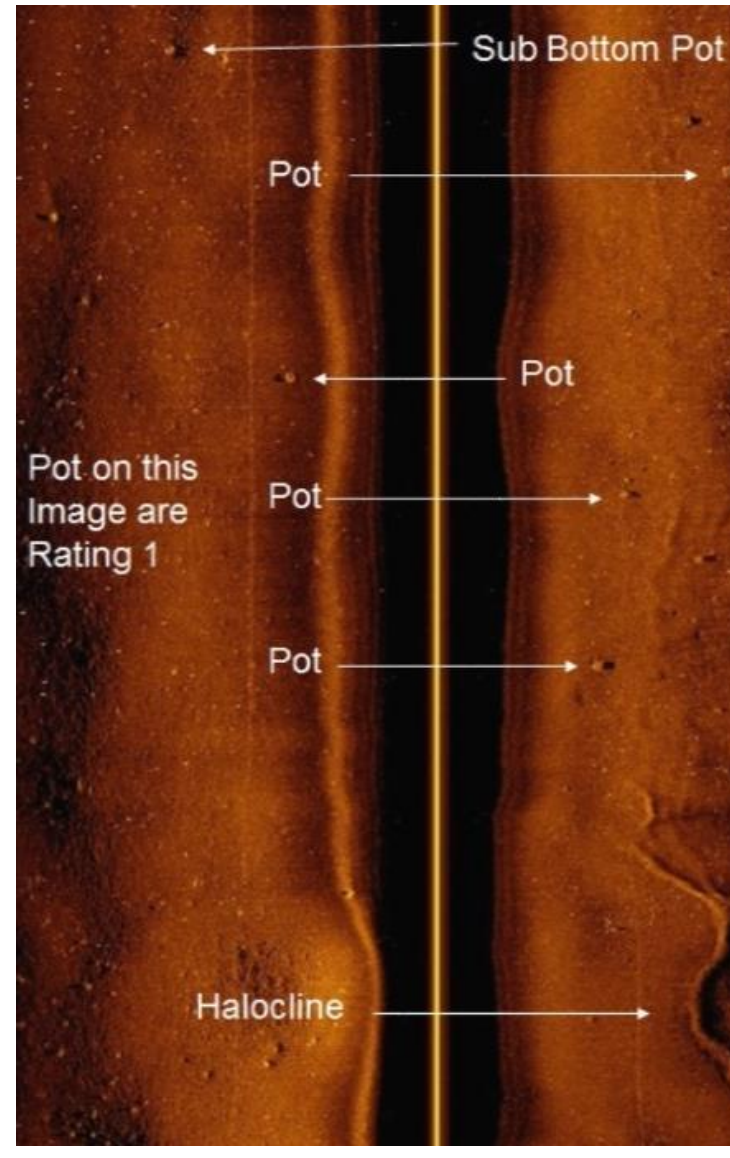

Contacts:

- Kyle Antonelis, Natural Resources Consultants, Seattle, Washington, USA, kantonelis@nrccorp.com

- Crayton Fenn, Fenn Enterprises, www.fennent.com

- Luiz Miguel Casarini, Scientific Researcher, Fisheries Institute of Sao Paulo State,

- lumicas@pesca.sp.gov.br

- Jared Berg, Monterrey Bay Diving, info@montereybaydiving.com 


\section{Case studies:}

Lost Fishing Gear Project, Brazil

Contact: Luiz Miguel Casarini, Scientific Researcher, Fisheries Institute of Sao Paulo State, lumicas@pesca.sp.gov.br

The Lost Fishing Gear Project involves a partnership between the Forestry Foundation and the Fisheries Institute of the Department of Agriculture of São Paulo State. The project is focused on mapping habitats within the Marine Protected Area around Brazil and removing abandoned or discarded fishing gear from the water. Sidescan sonar, a towed underwater camera, and a remotely operated vehicle (ROV) are used to conduct the surveys. This equipment has made it possible to detect ALDFG on the sea floor.

The project goal is to identify, quantify and map ALDFG and, in collaboration with conservation partners, promote preventive measures within the fisheries sector.

\section{Puget Sound, Washington, USA}

Contacts: Kyle Antonelis, Natural Resources Consultants, www.nrccorp.com, Crayton Fenn, Fenn Enterprises, www.fennent.com

Featured in this article: http://www.sea-technology.com/features/2010/0810/side scan sonar.html

In the Puget Sound program, contractors use a Marine Sonic sidescan sonar system operating at 600 $\mathrm{kHz}$ with a differential global positioning system (DGPS) to locate lost shellfish pots. To locate lost nets, surveyors use both $600 \mathrm{kHz}$ and $300 \mathrm{kHz}$, depending on the seafloor terrain and other factors. The sonar system employs a heavy towfish, towed off the bow of an $8 \mathrm{~m}(26 \mathrm{ft})$ survey vessel. A hydraulic winch and cable control the depth of the towfish. The sidescan sonar image is projected on a monitor onboard the vessel and recorded onto a computer hard drive for later processing.

The sidescan sonar survey is conducted at an average speed of $5.19 \mathrm{~km} / \mathrm{hr}$ ( $2.8 \mathrm{knots})$ with a sonar signal range from 20 to $50 \mathrm{~m}$ on either or both sides of the vessel depending on water depth, seafloor topography, gear type targets, haloclines, thermoclines, and other factors. Path width ranges from 20 to $100 \mathrm{~m}$ (66 - $328 \mathrm{ft}$ ) depending on chosen signal range and channels (port and/or starboard) used. Survey depths vary depending on the project area and client needs.

Counts and precise locations of ALDFG are recorded during post-survey processing of the data. The products from the sidescan sonar survey include a trackline file of the area surveyed, calculation of the area covered and the positions (latitude and longitude) of likely ALDFG targets found. 
North-Western Adriatic Sea, Italy - GHOST Project http://www.life-ghost.eu/index.php/en/ Contacts: Luisa Da Ros, CNR/ISMAR, luisa.daros@ismar.cnr.it, Federico Riccato and Riccardo Fiorin, Laguna Project, info@lagunaproject.it

The GHOST Project is a multi-partner project aimed at quantifying ALDFG impacts on rocky habitats in the north Adriatic Sea, locating and removing ALDFG, and preventing further impacts from ALDFG by working collaboratively with fishermen and fisheries agencies on prevention. The GHOST Project worked with divers to locate/survey for ALDFG and they used acoustic and underwater surveys to map the rocky outcrops, draw up high-resolution geo-referenced maps, and quantify ALDFG (and any other type of marine litter visualized). Acoustic surveys were carried out before diving operations when some specific circumstances, such as reduced visibility due to muddy water and only partial knowledge of seabed morphology, occurred. Acoustic surveys were carried out using a High Resolution Scanning Sonar (HRSS) head coupled with Windows( $r$ ) based Sonar Processing Software, which provided a very detailed HD snapshot of the target areas near (up to 100 meters) the sonar head.

The acoustic survey operations were carried out under stable sea and weather conditions. A grid of anchor points was prepared in advance from which surveys were conducted. On each grid point, the sonar head was lowered with a winch and installed on a tripod ensuring proper emplacement on the seabed and shock protection. The following sonar setting modes and operational procedures for field surveys were used for plotting points on the survey grid:

1. Use an operational distance of $100 \mathrm{~m}$ in radius around the sonar position;

2. If no outcrop / structure / ALDFG is detected within a $100 \mathrm{~m}$ radius, lift the equipment and place the vessel on the following spot to monitor;

3. If an outcrop / structure / ALDFG is detected, lower the equipment several times at close distance (the distance between the lowering points shall not exceed 50-60 m between them) in the area surrounding the first surveyed spot, to "shed light" on the structure from all angles and subsequently facilitate its digital imaging.

4. For each surveyed point, at least one image acquisition shall be obtained corresponding to seabed scanning within a radius of $100 \mathrm{~m}$ from the sonar position.

5. If the equipment has been placed near the outcrop / structure / ALDFG, images shall also be acquired with a lower radius $(10-30 \mathrm{~m})$, to scan the detected object with more details.

6. Each acquisition must be associated with the GPS position of the craft during echo-sounding operations (preferably with WGS-84 datum).

At the end of an acoustic survey, the team used a GIS plan image of the surveyed site, highlighting any existing anomalous or clearly anthropogenic structures. This map was the starting point for subsequent exploratory diving surveys. 


\section{Surface visual surveys}

\section{Boat-based surveys}

Visual surveys from boats are an excellent method to locate the buoys of lost shellfish traps or lost gillnets. However, boatbased surveys are best conducted in areas of high concentration of lost gear as fuel costs will prohibit extensive surveying in large areas with low concentrations of lost gear. This method is best used after closures of shellfish or trapbased fisheries where traps are abandoned or drift away from set locations. Many fisheries enforcement agencies use this method to locate lost traps, with removal occurring simultaneously.

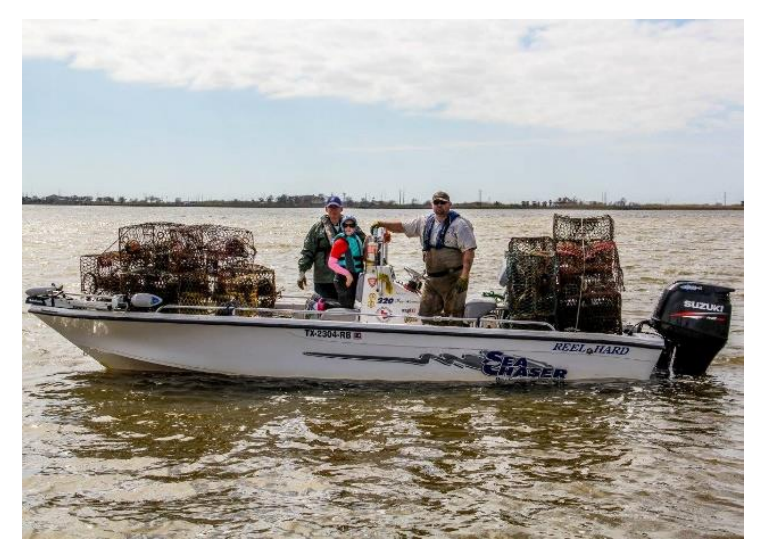

\section{Case Studies:}

\section{Gulf of Mexico, Texas, USA}

Contact: Zack Thomas, Texas Parks and Wildlife Department, Zack.Thomas@tpwd.texas.gov

Every year, for ten days in late February, Texas Parks and Wildlife organizes an all-out lost crab trap removal derby in numerous bays along the Texas coast. The removal efforts are boat-based using Shallow draft vessels, such as flat boats or air boats. Larger vessels are used to shuttle traps from the field to collection sites. Traps are located from the boats visually and hauled up using grapples or hooks. Texas Parks and Wildlife Department staff help to direct volunteers in boats to areas knowsn to have high concentrations of lost crab traps.

Area A Crab Fishery, British Columbia, Canada

Contact: Dan Edwards, Director, Area A Crab Association, Danedwards@telus.net

Each year after the crab fishery closes in northern British Columbia's Area A crab fishery, the Area A Crab Association hires a vessel to retrieve crab traps that were lost during the season. These retrieval operations are almost always done in conjunction with scientific surveys related to crab shell conditions (softshell surveys) conducted to determine appropriate season openings. The hired vessel is a member of the crab fleet and the captain and crew are familiar with areas of concentrated trap loss. During operations, the vessels visually search areas for buoys on the sea surface. When a buoy is sighted, the vessel approaches the location and the crew retrieves the trap with the vessel's pot puller. Thousands of lost traps have been retrieved through these operations over several years. The operations are paid for with membership fees paid by the fishers to the Area A Crab Association. 


\section{Aerial surveys}

Visual surveys from airplanes flying at low altitude have successfully located derelict shellfish pots where buoys remain on the surface of the water. This method has been used successfully off of the West Coast of Washington and Oregon to locate lost Dungeness crab pots.

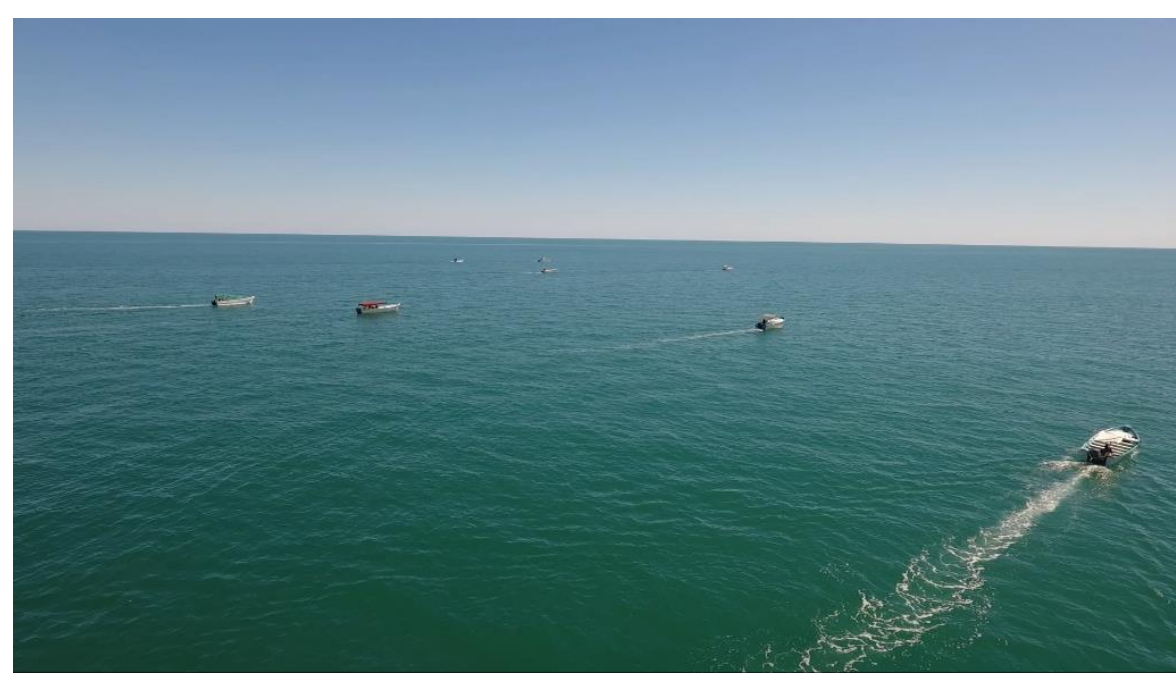

\section{Case study:}

\section{West Coast, Washington, USA}

Contacts: Kyle Antonelis, Natural Resources Consultants, kantonelis@nrccorp.com, Joe Schumacker, Quinault Indian Nation, jschumacker@quinault.org

The intent of the aerial surveys conducted for the Quinault Indian Nation was to quantify the amount and spatial extent of derelict crab pots in the project area (West Coast of Washington State) and to document locations of high derelict pot concentration areas. Aerial surveys were conducted from a fixed-wing aircraft piloted by a for-hire pilot with experience as a spotter pilot in Alaska fisheries, with one project team member as passenger to collect pot target locations. During surveys, the aircraft maintained an elevation of approximately 1,300 feet at a speed of 120 miles per hour. Multiple passes along the length of the survey area were conducted with spacing one to two miles apart, beginning nearshore along the breaking waves and finishing approximately five miles west of the shoreline at the 15 to 20 fathom (90 to 120 feet) ocean depth contour.

Upon visual sighting of crab pot buoys, latitude and longitude coordinates were collected with a handheld GPS unit and their location relative to the aircraft was noted. Each observed pot or concentration of pots was assigned an identification number and the number of pots for each identification number was noted. All data was stored in MS Excel and converted to waypoints in navigation software to be used during removal operations and reporting. The products of the aerial surveys include descriptions of the area surveyed and locations of derelict crab pots and concentrations of pots identified. This process proved to be very useful to identify areas for targeted gear removal; however, target coordinate precision was coarse. Additionally, presence of seabirds and whitecaps can present false-positive target identification. 


\section{Underwater diver surveys and drop camera surveys}

Many programs have successfully worked with divers to survey identified areas of suspected concentrations of lost fishing gear to both provide exact locations of gear to be removed and to verify that targets (in the case of sidescan sonar surveys, etc.) are ALDFG. In NOAA's program in Hawaii, divers using snorkeling gear and holding onto boards attached with ropes to slow-moving boats survey swaths of habitat in the Northwest Hawaiian Islands. Hand signals are used to notify boat crews of the presence of gear. In Puget Sound, divers are regularly employed to verify gear targets identified in sidescan sonar surveys. Also, divers in Puget Sound were employed to visually survey reefs where sonar is ineffective. Under these operations, divers were towed behind a slowmoving vessel or climbed over rock faces.

Drop camera surveys have been used in several locations, mostly in conjunction with diver surveys and with sonar surveys for verification.

Diver surveys and drop camera surveys are limited by the visibility of the water.

Contacts:

James Morioka, NOAA PIFSC Coral Reef Ecosystem Program, Operations and Marine Debris Team, james.morioka@noaa.gov

Kyle Antonelis, Natural Resources Consultants

kantonelis@nrccorp.com

\section{Case Study}

\section{Northwest Hawaiian Islands, USA}

Contact: James Morioka, NOAA PIFSC Coral Reef Ecosystem Program, Operations and Marine Debris Team, james.morioka@noaa.gov

For several years, NOAA conducted lost fishing gear and other marine debris removal operations in the remote Northwest Hawaiian Islands. These small islands and atolls are home to the endangered monk seal, a species known to be vulnerable to entanglement in fishing gear. Divers surveyed the shallow areas visually using snorkel equipment. They were towed behind a 15 -foot inflatable boat holding on to towboards: rectangular wood boards measuring about $1 \mathrm{ft}$ by $3 \mathrm{ft}$. Two divers were towed at one time, keeping about seven feet apart. Diver's would manipulate the boards to search for fishing gear, moving up and down in the water column to about 15 -foot depth. When gear was spotted, the diver would release the board and signal with their hand to the boat, then wait for the boat to return and begin the retrieval of the gear. A spotter on the boat would watch for divers' hand signals at all times.

Surveys were tracked with GPS and focused on GIS produced polygons of areas with high risk of monk seal entanglement 


\section{Dragging or Grappling Surveys}

In areas where concentrations of lost fishing gear are known or suspected to occur, systematic dragging of grapples or arrays of hooks can effectively locate gear. In some instances, removal can be accomplished immediately after location using the same grapples, or hooks to remove the gear. In other instances, locating the gear through dragging is followed by either noting the location of the gear or by marking the location in situ with

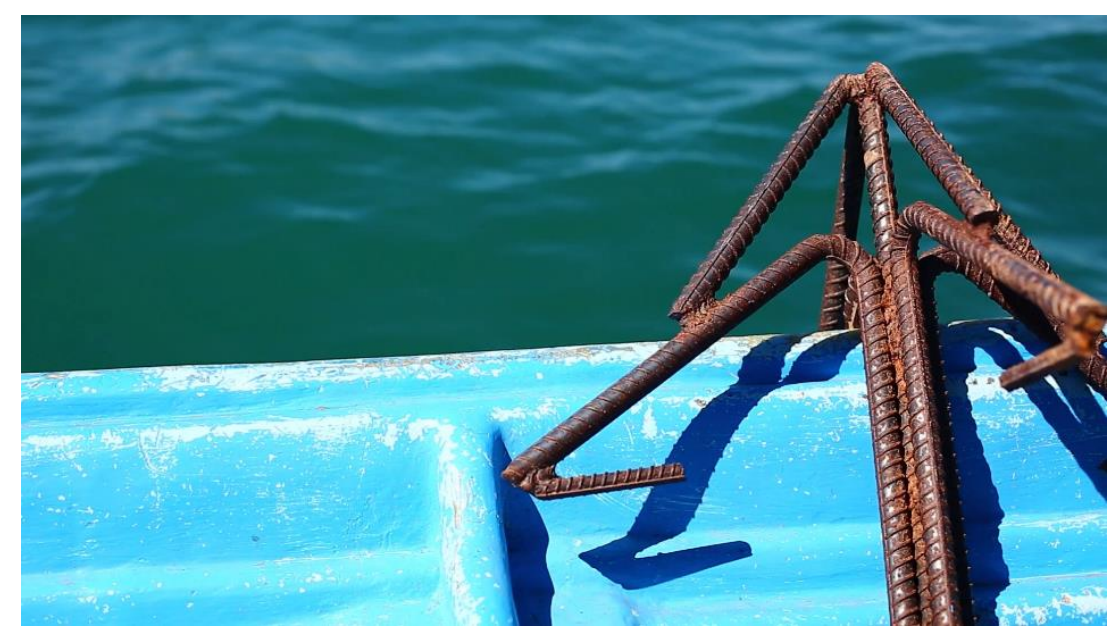
buoys or other means.

This method can be effective in habitats with sandy or muddy bottoms and little rugosity. In reef areas or seagrass beds, the method can cause excessive damage to marine habitats.

**Project managers exploring grappling, dragging, or creeping to locate lost fishing gear should investigate the locations of underwater utilities and fiber optic cables in the project area. It should be noted that cables have been placed on the seafloor all over the world, including in some of the most remote ocean areas. Some cables are indicated on nautical charts. An internet search related to underwater cables in a project area should lead to maps of cable locations. One good general source for locations of underwater cables is http://www.submarinecablemap.com/.

\section{Case Study}

\section{Gulf of California, Baja, Mexico}

Contact: Lorenzo Rojas Bracho, Instituto Nacional de Ecología y Cambio Climatico, Irojasbracho@gmail.com

A press release about the program can be found here:

https://www.gob.mx/semarnat/prensa/retiran-redes-fantasma-en-el-alto-golfo-de-california-paraproteger-a-la-vaquita-marina

In the Gulf of California, local fishermen were employed to survey transects within a designated area, to locate lost or illegal fishing gear (mostly gillnets) suspected of negatively impacting the endangered vaquita (Phocoena sinus). Fishermen used their own pangas (small fishing boats with outboard motors) and simple grapples. At least 19 pangas and $40 \mathrm{crew}$ were employed in this program. Fishermen motored along pre-designated transect lines with grapples deployed. When grapples snagged fishing gear, it was pulled up to the surface, a buoy was attached to it, then released. Subsequently, larger vessels followed the surveys and removed the gear. 
During 21 days (1,500 hours) of search operations covering 11,814 kilometers between October 10 and December 7, 2016 a total of 136 items of abandoned fishing gear were discovered, of which 103 were retrieved: 36 illegal gillnets for totoaba (28 active); 36 illegal gillnets for shrimp; 24 longlines to capture totoaba, sharks and other fish (80-500 meter in length, all in bad conditions); and 7 trawl nets and traps. Fishing gear, once marked to assist in its detection and retrieval, was removed from the sea immediately to prevent its recovery by illegal fishermen. The larger vessels assigned to remove the nets detected by the pangas removed more than 9.35 tons of gear, which was delivered to a recycling center. Fishing gear, once marked to assist in its detection and retrieval, was removed from the sea immediately to prevent its recovery by illegal fishermen.

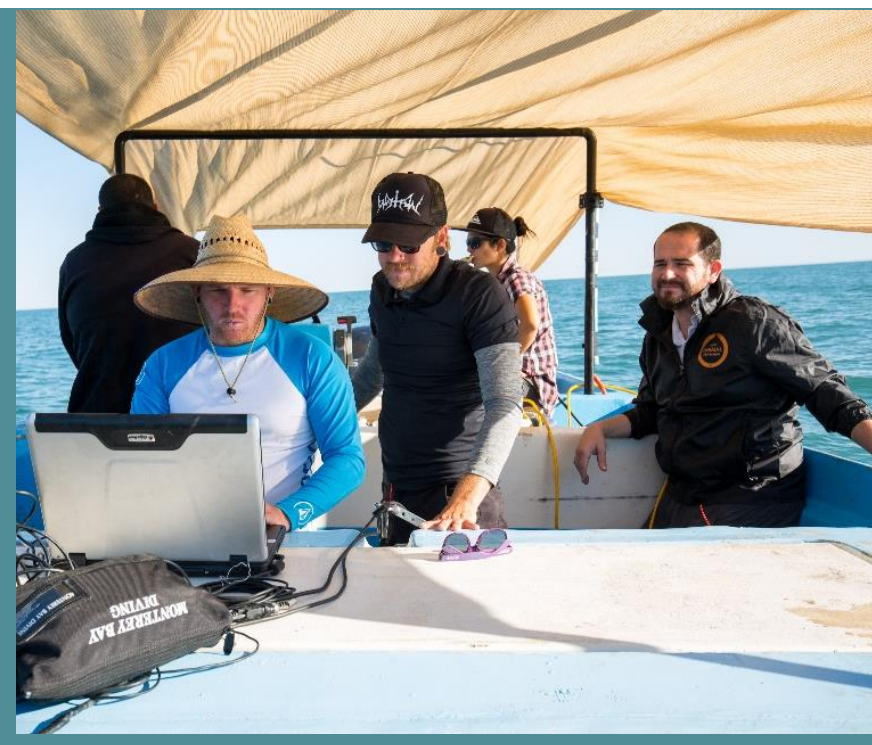

\section{Accessing local knowledge of fishing gear loss, including fisheries data}

Several programs have relied on fishers to direct them to areas or locations where fishing gear is lost. Immediate reports from fishermen related to lost gear are the most reliable. In Pakistan, the Olive Ridley Project collaborates with fishers who lead dive teams by boat to the exact locations where nets were lost. In Puget Sound, the Northwest Straits Foundation manages a newly lost fishing net Reporting, Response, and Reporting program that includes phone and online reporting, and a rapid response process that includes on-call dive teams for net removals. The system accepts real time reports of lost fishing nets from fishers and other reporters.

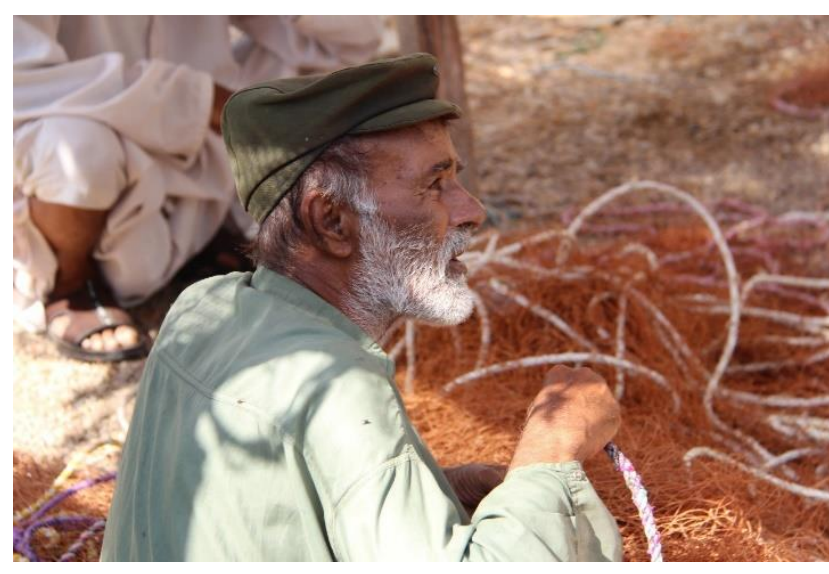

Fisher and diver interviews have also proved fruitful in identifying areas or locations of concentrations of lost gear. While this method is not real time, it has proved very accurate in identifying 'hot spots' of concentrated gear. Fathoms Free, a Cornwall, UK based volunteer-led community group that supports regular dive cleanups of ALDFG and ocean plastics, often organize their removal operations triggered by a report of lost fishing gear sighting by the project partners such as Cornwall Seal Group Research Trust, British Divers Marine Life Rescue, local dive clubs and other sea users. Ghostfishing, a Netherlands-based dive removal organization, uses reports from divers to focus lost fishing gear removal efforts, often on shipwrecks. 
A number of organizations encourage divers to report any lost fishing gear found. They use this reporting information to build awareness and also to plan cleanup activities. Project Aware has developed a mobile phone and internet application that allows divers to report locations of any marine debris found while diving: https://www.projectaware.org/news/use-your-phone-take-actionclean-ocean. Ghostfishing UK has an online reporting form for divers to report locations and type of gear found while diving:

https://docs.google.com/forms/d/e/1FAlpQLSeR9iap0wMz9Q2gIWcfQjHajsna-OWTPFjupXwmwYQAwKLVQ/viewform. They have also developed a means to report locations and types of lost fishing gear on seven wrecks present at Scapa Flow: http://www.bigscapacleanup.co.uk/maps/. They are using these reports to plan cleanup activities at Scapa Flow.

Ocean researchers are also good sources of information. Oceanographers using remotely operated vehicle or trawl surveys are likely to come across lost fishing gear and can often provide accurate locations and even visual images of gear. In Puget Sound, the Northwest Straits Foundation has received valuable information and exact locations of lost fishing gear from researchers at the Washington Department of Fish and Wildlife from both research dives, and ROV surveys.

\section{Contacts:}

Pascal Van Erp, Ghostfishing, pascal@ghostfishing.org

Rob Thompson, Fathoms Free, rob@fathomsfree.org

Martin Stelfox, Olive Ridley Project, martin@oliveridleyproject.org Jason Morgan, Northwest Straits Foundation, morgan@nwstraitsfoundation.org

\section{Case Studies:}

\section{Norwegian Directorate of Fisheries, Norway}

Contact: Lise Langard, Norwegian Directorate of Fisheries, lise.langard@fiskeridir.no https://www.fiskeridir.no/English/Fisheries/Retrieval-surveys-for-lost-gill-nets

The Norwegian Directorate of Fisheries has been implementing a lost gear location and recovery program for over thirty years and have so far retrieved over 20,000 gillnets. The focus is on locating and retrieving gillnets due to the severe impact of lost gillnets on commercial catch rates, particularly of Greenland halibut. They plan the locations of their removal work using a combination of VMS data to identify the most commonly used fishing grounds, direct interviews with fishermen, a reporting form and then boat-based surveys. For the removal operations, the government hires a fishing vessel and undertakes a sweep / drag retrieval operation using three anchors attached directly to a trawl.

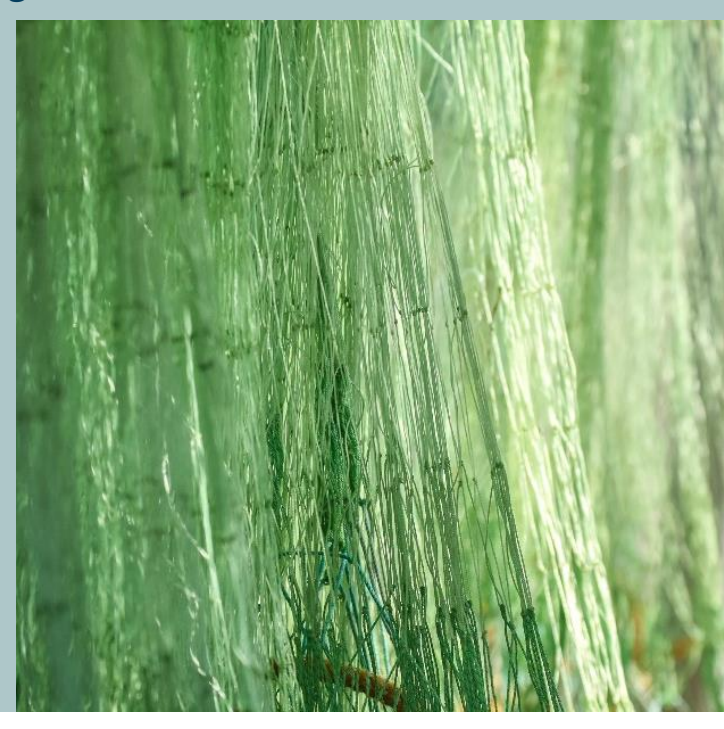




\section{Neptune's Army of Rubbish Cleaners and the Pembrokeshire Sustainable Shellfish Initiative, Wales, UK \\ Contact: Sue Burton sacofficer@pembrokeshiremarinesac.org.uk (PSSI), David Kennard: \\ DavidKennard4@aol.com (NARC)}

The Pembrokeshire Sustainable Shellfish Initiative (PSSI) is a partnership between lobster fishers and government to improve fishing sustainability and decrease ghostfishing through voluntary measures such as gear tagging, biodegradable hooks, escape hatches and v-notching female lobsters. The PSSI works closely with the environmental diving group, Neptune's Army of Rubbish Cleaners (NARC), to share information about locations of lost gear, potential hotspot areas of accumulation and collaborative removal opportunities.

\section{Ghostfishing, the Netherlands \\ Contact: Pascal van Erp, pascal@ghostfishing.org}

Ghostfishing executes lost fishing net removal projects in multiple locations, including the North Sea, the Mediterranean, Malta, and Greece. They rely on local divers and fishermen to tell them where gear is located before a mission is planned and executed. Local volunteer divers will identify gear locations, often on shipwrecks, conduct reconnaissance dives and sometimes collect video to assist with removal planning.

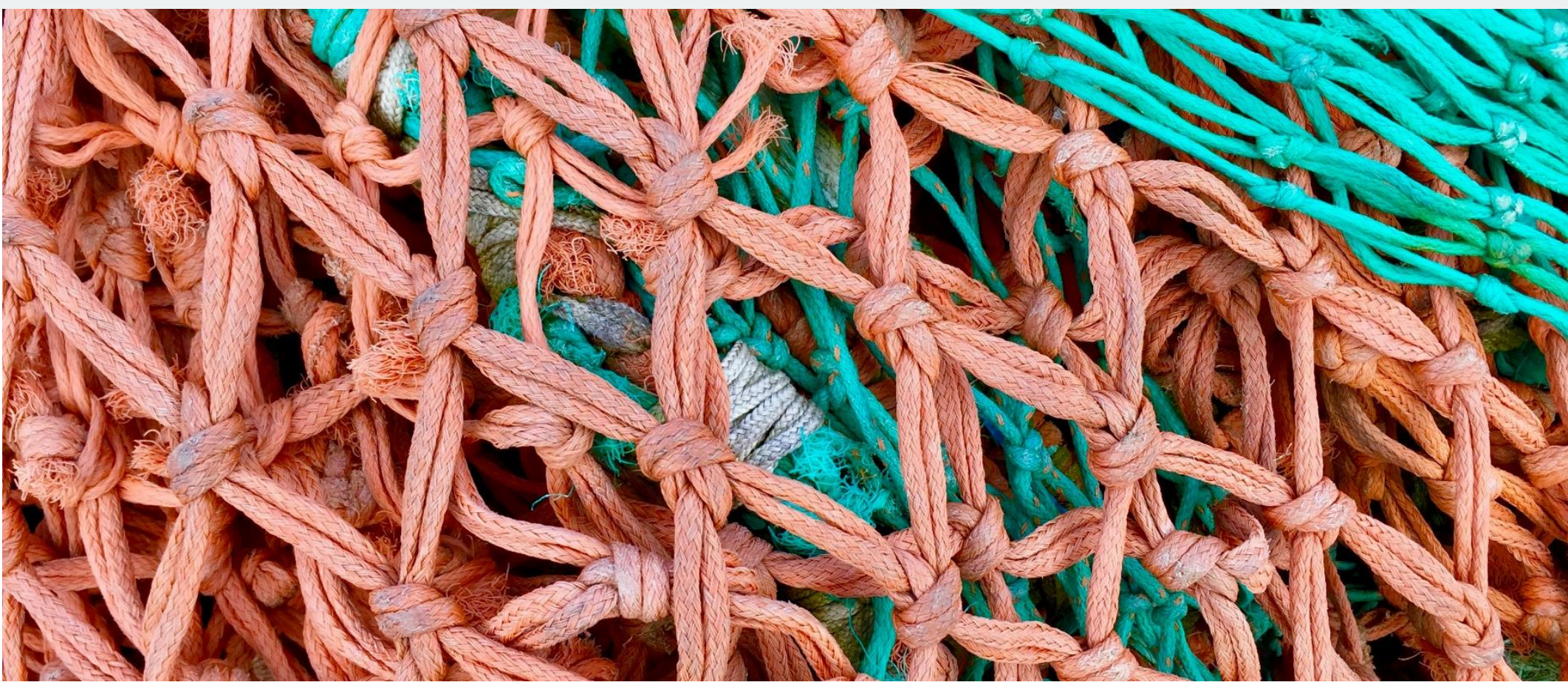

Methods to locate derelict fishing gear 